\title{
Setting up district audit meetings in psychiatry
}

\author{
DAvid Roy, Consultant Psychiatrist, St Thomas' Hospital, London SE1 7EH
}

Charles Shaw, in a number of articles and his Hospital Handbook (Shaw, 1989, 1990) has played a key role in outlining the principles of medical audit. He arbitrarily divides the process of medical audit into four phases. The philosophical phase which seems to have been negotiated, is whether the medical profession should be involved; the organisational phase; who should lead the process, and the resources required; the practical phase, what should be audited and the methods used; and the invasive phase, how the general concepts and the details of audit are communicated through publication. He goes on to describe a variety of methods of audit including the review of adverse events and general statistics, the assessment of randomly selected records, and finally the review of a topic (which includes medical record review). Another approach in planning audit is through understanding of the organisation itself (Donabedian, 1966) and evaluating quality of care in terms of the structure of the organisation (bricks and mortar, staffing, beds, technology etc.), the process of care, and this may include length of stay, broad out-patients statistics, and perhaps more controversially, face to face contact, group interaction, home visits, day hospital attendance and so on. Finally, and most complex, is outcome.

Outcome measures in psychiatry are complicated, and clearly reproducible but simple quality of life measures are not available. Diagnoses are often not agreed upon, and are probably only helpful in relating to service provision, resource allocation, and need assessment if they are much more detailed than the current Korner requirements or ICD-9. Multiaxial systems may assist, and the clinical modification (CM) codings of DSM-111-R and ICD are an advance, although not widely used as yet. It is illusory, however, to suggest that psychiatry is alone in grappling with these issues, and medicine, which has made considerable advances in audit recently, has similar difficulties.

All doctors employed in the NHS will be required to participate in regular audit by 1991, and many districts have established audit committees comprising representatives of key specialties. It is expected that these committees will facilitate audit in the district, identifying resource implications, monitoring progress throughout the district and distribut-

This article was written while $\operatorname{Dr}$ Roy was Consultant Psychiatrist at Goodmayes Hospital, Ilford, Essex. ing information on ongoing audit within other specialties.

Each district may have identified pyschiatrists prepared to act as co-ordinators and participate in the district committee. College guidelines in psychiatry have yet to be finalised, but it would seem sensible for each region to have an 'audit in psychiatry' committee comprising district co-ordinators plus sub-specialty representation along the lines of the Regional Education Committees, and as a sub group of the regional advisory machinery.

\section{Suggested tasks of the audit co-ordinator}

\section{Organisational}

(a) Agree basic principles with colleagues

Without the agreement of all consultants to participate actively in the audit process, smaller districts could find their audit effectively sabotaged.

There is a suggestion in a recent health service draft circular (Medical Audit EL(90)P/28) that where there is unresolved concern about a particular service, the district audit committee may initiate an independent review. This may take the form of peer review by clinicians from outside the district, or a joint professional and management assessment of the service. In addition, the role of monitoring bodies in relation to audit, and the service in general has yet to be clarified.

\section{(b) Structure and regularity of meetings}

All trainees and senior registrars should attend as part of training, and it is likely that our College will make this a mandatory requirement for approval of training in line with the Royal Colleges of Physicians and Surgeons.

The health service circular suggests one session per week, but it is hard to see how most district services would be able to modify their psychiatric resource base to accommodate this demand. One session per month would seem a reasonable short term aim, although organisation will inevitably take up more time.

\section{(c) The initial audit meeting}

A preliminary audit meeting should be held to agree topics and the process of audit appropriate to that 
topic. Criteria should be agreed and tasks allocated. Some audit can usefully be undertaken in the form of a simple prospective or retrospective research project. The topics need to be interesting and wide ranging enough to usefully influence practice as part of the feedback loop (setting standards, measuring practice and effecting change). After the presentation of general data and discussion, there usually follows random case note reviews with agreed selected criteria, according to broad diagnoses or topic. The criteria are not value judgements passed on clinical practice but basic measurable items such as length of stay, investigations, mode of referral, follow up, communication and general outcome measures, if available.

\section{(d) Technical aspects}

Regular audit meetings will no doubt serve to highlight the woefully inadequate data technology systems generally available in the NHS and how far we lag behind countries with well established audit procedures. Attempts by management to stonewall audit by refusing to allocate reasonable manpower towards retrieving simple information should be strongly resisted. "It is the responsibility of local managers to ensure that adequate resources are available to support agreed audit ... support staff and appropriate systems will be necessary in all units". (Draft Health Circular EL(90)P/28 7 February 1990.)

One way of moving forward will be to develop very clear ideas about what information is required in each specialty. These systems will only follow regular audit meetings. District audit committees have been instructed to assist in the development of "common databases and formats".

\section{Communication and liaison}

(a) The presence of a strong voice on district and regional committees is essential, and psychiatrists should have a clear idea of funding required for the programme to get under way, and to ensure a slice of the cake.

(b) The minutes of regular audit meetings helpensure review of the feedback loop, as well as keeping management informed of the progress of the meetings to have maximum impact. The naming of wards, consultant teams or patients when highlighting special difficulties and clinical details has no place in these minutes although comparative data such as drug expenditure by ward or consultant or admission rates are often usefully disseminated and generally available through management systems already.

We are now entering a phase of audit in psychiatry with a somewhat clearer idea about selection criteria, some positive feedback on influencing clinical practice and the managers in the district, and more information on information, or the lack of it.

\section{References}

DONABEDIAN, A. (1966) Evaluating quality of medical care. Millbank Memorial Fund Quarterly, 44, 166-206.

Shaw, Charles (1989) Medical Audit. A Hospital Handbook. London: King's Fund Centre.

Shaw, C. D. (1990) Criterion based audit. British Medical Journal, 300, 649-652. 